\title{
Treatment of Basal Cell Cancer With a Pulsed Copper Vapor Laser: A Case Series
}

\author{
Svetlana V. Klyuchareva ${ }^{1}$, Igor V. Ponomarev ${ }^{2 *}$, Sergey B. Topchiy ${ }^{2}$, Alexandra E. Pushkareva ${ }^{3}$, Yury N. \\ Andrusenko ${ }^{4}$
}

'Department of Dermatovenereology, I.I. Mechnikov North-Western State Medical University, 47, Piskarevkiy Prospect, St. Petersburg, 195067, Russian Federation

${ }^{2}$ P.N. Lebedev Physical Institute of the Russian Academy of Sciences, 53, Leninskiy Prospect, Moscow, 119991, Russian Federation

${ }^{3}$ Saint Petersburg National Research University of Information Technologies, Mechanics and Optics, 49, Kronverkskiy

Prospect, St. Petersburg, 197101, Russian Federation

${ }^{4}$ Medical Center "Health Institute," Kharkiv, 61000, Ukraine

*Correspondence to

Igor V. Ponomarev, Ph.D.; P.N.

Lebedev Physics Institute, RAS,

Moscow, Russia.

Tel: +7-9164049519

Email: iponom@okb.lpi.troitsk.ru

Published online October 1, 2019

\begin{abstract}
Introduction: Basal cell carcinoma (BCC) is the most prevalent form of non-melanoma skin cancer commonly arising in elderly patients. Currently, many laser systems are applied for the treatment of BCC. However, up to the present, there have been several reports concerning ocular side effects due to the laser procedure in the borders of the periorbital area. This determines the feasibility of testing new laser surgical modes for the management of periorbital BCC. This stuay aimed to estimate both the efficacy, the early post-radiated side effects and long-term outcomes of the CVL treatment of periorbital BCC.

Patients and Methods: Two men and 6 women aged 50 to 77 years were diagnosed with periorbital BCC according to the data of both the clinical evaluation and histological examination of the tissue samples taken from the involved area. Six months after the laser treatment, the histological examination of skin samples from the borderline of the irradiated area was made again. All patients were followed for 24 months after the laser treatment of BCC. The laser treatment was administered during one session of copper vapor laser (CVL) (Yakhroma-Med model). The treatment included CVL radiation with a wavelength of $511 \mathrm{~nm}$ and $578 \mathrm{~nm}$, in the ratio of 3:2. The power level was set up to $3 \mathrm{~W}$, and the exposure time was equal from 200 to $600 \mathrm{~ms}$. The pulse duration accounted for $15 \mathrm{~ns}$. The diameter of the light spot on the skin surface amounted to $1 \mathrm{~mm}$.

Results: Dual-wavelengths CVL treatment of periorbital BCC provided a complete elimination of malignant cells and dysplastic vessels during one procedure. The duration of skin healing amounted to 2-4 weeks. There were neither ocular injuries or pronounced skin side effects nor relapses within 24 months after the laser procedure.

Conclusion: CVL treatment of periorbital BCC provides relevant cosmetic results without ocular injuries and relapses.

Keywords: Periorbital BCC; Copper vapor laser; Ocular injury; Selective vascular heating.
\end{abstract}

\section{Introduction}

Occurred mostly in fair skin people, basal cell carcinoma (BCC) is commonly located at the face, including periorbital area. BCC was proved to be related to the ultraviolet radiation (UVR) damage of mitochondrial and nuclear DNA in keratinocytic stem cells of the epidermal basal layer. ${ }^{1}$ The sun exposure damage to basal keratinocytes is mediated via the UVR absorption by DNA with the following extgeneration of free radicals and mitochondrial oxidative stress. ${ }^{2}$ Following both nuclear DNA and mitochondrial RNA impairments along with PARP insufficiency are known to deteriorate as the natural behavior of epidermal basal melanocytes and keratinocytes as their interaction with related sebocytes and endothelial cells. ${ }^{3-5}$ So far the pathogenesis of BCC is associated with both dysfunction of keratinocytes and melanocytes of the basal layer of the epidermis and the abnormal transformation of the vascular bed in the BCC underlying papillary dermal layer. ${ }^{6-8}$ According to the data reported in recent bench-to-bedside investigations, the pathogenetic treatment of BCC must provide the elimination of both all-malignant keratinocytes and melanocytes supporting the progression of the malignant process in the basal layer of the epidermis and the pathological vascular dysplastic bed in the adjacent dermal papillary layer. Up to the present, there has been appeared a number of reports concerning the sound application of such laser systems as pulsed dye laser, diode, $\mathrm{Nd}$ :YAG, and CO2 laser system

Please cite this article as follows: Klyuchareva SV, Ponomarev IV, Topchiy SB, Pushkareva AE, Andrusenko YN. Treatment of basal cell cancer with a pulsed copper vapor laser: a case series. J Lasers Med Sci. 2019;10(4):350-354. doi:10.15171/jlms.2019.57. 
for the treatment of BCC. These systems allow in many cases achieving the complete regression of primary BCC at the stage of $\mathrm{T}_{1-2} \mathrm{~N}_{0} \mathrm{M}_{0}{ }^{9}$ Whereas some laser systems use the radiation that is not mostly absorbed by neither melanin nor oxyhemoglobin, laser light can reach the reticular layer of the dermis or even deeper to cause such ocular injuries as pain above and behind the eye, blurred vision, and photophobia. ${ }^{10}$ Thus it seems important to adopt new modes of laser surgical treatment management of BCC located near an eye.

As mentioned above, the use of the dual-wavelength copper vapor laser (CVL) radiation seems to be promising for the relevant pathogenetic laser treatment of BCC, as the CVL radiation with a wavelength of $511 \mathrm{~nm}$, mainly absorbed by melanin, promotes the elimination of the malignant basaloid cells. The radiation with the wavelength of $578 \mathrm{~nm}$, mostly absorbed by oxyhemoglobin and deoxyhemoglobin, provides the complete photothermal occlusion of the BCC ectatic vascular bed in the papillary dermal layer. Due to the high absorption of $511 \mathrm{~nm}$ CVL radiation by melanin and $578 \mathrm{~nm}$ CVL radiation by oxyhemoglobin and deoxyhemoglobin, the penetration of CVL laser limited by the dermal papillary layer prevent the ocular exposure to laser light.

\section{Patients and Methods}

Two men and 6 women, aged 50 to 77 years, were diagnosed with $\mathrm{BCC}$ at the $\mathrm{T}_{1-2} \mathrm{~N}_{0} \mathrm{M}_{0}$ stage according to clinical evaluation and histological examination of tissue samples taken from the affected area and the borderline zone (Table 1). BCC was located at the lower eyelid in four cases, at the upper eyelid in 2 cases, at the nasal bridge close to the eye corner in one patient, and under the eyebrow in 1 case (Figurs 1-5). The BCC was detected to be of the nodular subtype in 7 cases and the infiltrative subtype in the one patient. The informed consent for the laser treatment of BCC with CVL was obtained from all patients. The BCC treatment was performed under local infiltration anesthesia with Sol. Articaine hydrochloride $4 \%$ with 1:200 000 epinephrine in a dose of $1.7 \mathrm{~mL}$. Just after the procedure, a dry scab was formed immediately (Figure 1a). The skin was treated with chlorhexidine; (a)
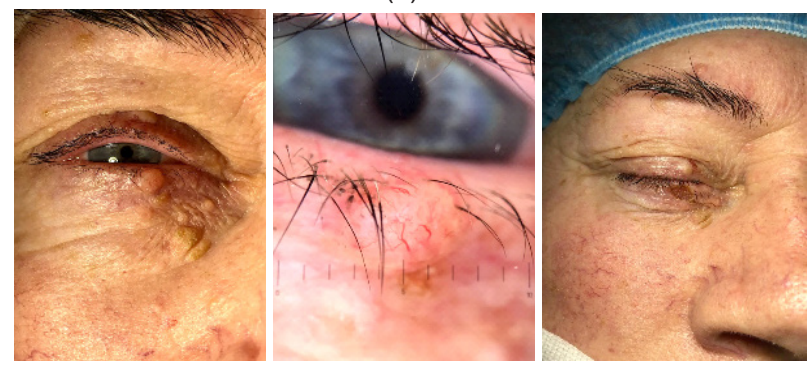

(b)

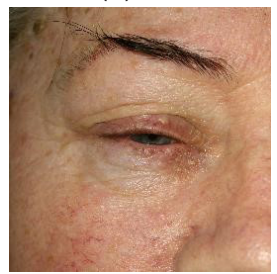

Figure 1. (a) BCC on the right lower eyelid before and immediately after CVL treatment (Patient \#1 Table 1 Stage IA $\left(T_{1} N_{0} M_{0}\right)$ ). (b) The post-treated area on the right lower eyelid 5 months after the laser procedure.
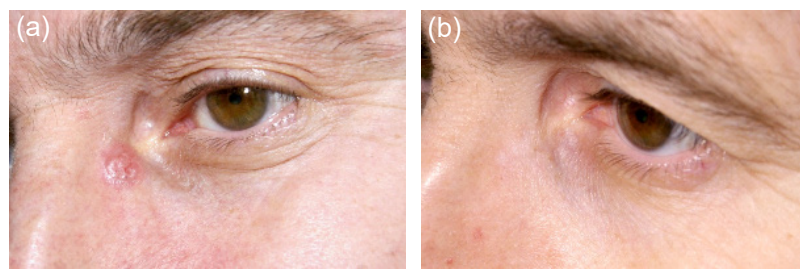

Figure 2. Nodular BCC on the nasal bridge, left, before $(\mathbf{a})$ and 2 months after (b) CVL treatment. (Patient \#2 Table 1). Stage I $\left(\mathrm{T}_{1} \mathrm{~N}_{0} \mathrm{M}_{0}\right)$.

then, the epithelizing gel was applied 2 times a day until the crust fell off.

Six months after the laser treatment in all the treated patients, the tissue samples from the borderline of a post-radiated area were examined (1) for the presence of atypical cells. All patients were followed for 24 months after the laser treatment.

Laser Surgical Technique

The laser treatment was performed with the use of

Table 1. Description of patients

\begin{tabular}{|c|c|c|c|c|c|c|}
\hline No. & Age $(y)$ & Gender & Location & Histological Subtype & Dimensions (mm) & Healing Time (wk) \\
\hline 1 & 68 & Female & Inferior eyelid right & Nodular & $5 \times 4$ & 2 \\
\hline 2 & 51 & Male & Nasal bridge left & Nodular & $8 \times 7$ & 2 \\
\hline 3 & 77 & Female & Inferior eyelid left & Nodular & $5 \times 5$ & 3 \\
\hline 4 & 45 & Female & Upper eyelid left & Nodular & $10 \times 7$ & 3 \\
\hline 5 & 60 & Female & Under the eyebrow left & Nodular & $15 \times 12$ & 3 \\
\hline 6 & 34 & Female & Upper eyelid left & Ulcerative & $10 \times 8$ & 2 \\
\hline 7 & 40 & Female & Inferior eyelid left & Nodular & $3 \times 3$ & 2 \\
\hline 8 & 50 & Male & Inferior eyelid left & Nodular & $7 \times 9$ & 3 \\
\hline
\end{tabular}




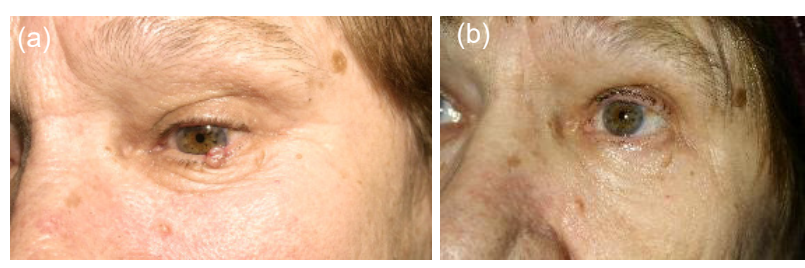

Figure 3. Nodular BCC on the left lower inferior eyelid, left, before (a) and three months after (b) CVL treatment. (Patient \#3 Table 1). Stage IA $\left(\mathrm{T}_{1} \mathrm{~N}_{0} \mathrm{M}_{0}\right)$.

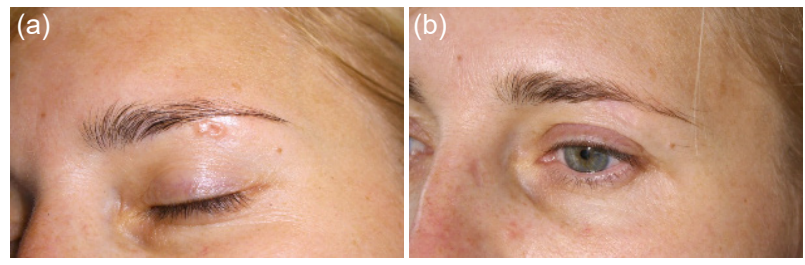

Figure 4. Nodular BCC under the left eyebrow, before (a) and 2 months after (b) CVL treatment. (Patient \#4 Table 1). Stage I $\left(\mathrm{T}_{1} \mathrm{~N}_{0} \mathrm{M}_{0}\right)$.
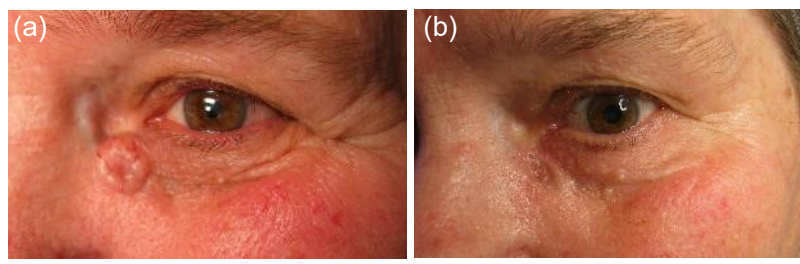

Figure 5. Nodular BCC on the periocular zone, before (a) and 3 months after (b ) CVL treatment. (Patient \#5 Table 1). Stage I $\left(\mathrm{T}_{1} \mathrm{~N}_{0} \mathrm{M}_{0}\right)$.

CVL (Yakhroma-Med model developed at the Lebedev Physical Institute of the Russian Academy of Sciences). The affected area was irradiated with dual-waves laser light of 511 and $578 \mathrm{~nm}$ in the ratio of 3:2 in the pulsed mode with a train of pulses with the duration of $15 \mathrm{~ns}$ and a repetition rate of $16.6 \mathrm{kHz}$. The average power was set up at $3 \mathrm{~W}$ with an exposure time ranging from 200 to $600 \mathrm{~ms}$. The fluence ranged from 30 to $300 \mathrm{~J} / \mathrm{cm}^{2}$. Laser radiation was focused on the patient's skin in a light spot with a diameter of $1 \mathrm{~mm}$. Safety shields were used to protect the patients' eye during the procedure. All the involved area and adjacent tissue of $5 \mathrm{~mm}$ along with the total borderline of the surrounding intact skin area were irradiated. The treatment was implemented during one CVL session.

\section{Results}

According to the clinical examination, after the healing of the post-radiated area, the complete BCC regression was achieved in all cases (Figures 1-5, b). In the early postradiated period, there were neither noted pronounced side effects nor ocular injuries. The procedure was followed by a mild swelling resolved after two days. The healing time lasted for 2 and 3 weeks (Table.1). In the involved area, flat atrophic hypopigmented scars instead of BCC were formed (Figures 1-5 b). In the tissue samples taken 6 months after the laser procedure from the borderline around the affected post-radiated area, neither basaloid cells nor disfigured keratinocytes were found.

No recurrences was observed during the entire observation period up to 24 months after treatment. All patients expressed satisfaction with the cosmetic effects of the CVL treatment.

\section{Discussion}

Several various modes of the management of skin BCC have been reported.

Laser parameters used for the BCC treatment are presented in Table 2. The high efficiency of the laser destruction of BCC was observed at the first stage of tumor development. ${ }^{11}$ The prevalence of BCC recurrences varied up to $15 \%{ }^{12}$ in the first 5 years after removal by laser destruction.

Nevertheless, there is no available report concerning the laser treatment of BCC located in the periocular area. Up to the present time, the laser procedures in the vicinity of the periocular zone have been reported to be related to the risk of ocular injuries involving the sore eye, blurred vision, photophobia, damage to iris, conjunctival injection, endothelial keratic precipitates, and cells in the anterior chamber. ${ }^{10-18}$ Compared the above data from CVL treatment of periorbital BCC with the rate of ocular injuries due to the facial laser procedure with other lasers, CVL treatment seems to be safer, as the use of another laser in facial cosmetic treatment is reported to be associated with ocular injury rate of $33 \%, \chi^{2}=3.515$, $P<0.06^{19}$.

Abnormal blood vessels of increased diameter, which are essential for the delivery of oxygen and nutrients to the growing $\mathrm{BCC},{ }^{20-21}$ can be selectively coagulated by a laser using the principle of selective photothermolysis. To date, the effectiveness of a pulsed dye laser (PDL), which has been successfully used for the selective photodestruction of vessels of increased diameter as a non-surgical method for the treatment of BCC, has been confirmed in some studies ${ }^{12-14}$. Despite the relatively low frequency of metastasis of $\mathrm{BCC},{ }^{22}$ a recurrence rate after the PDL treatment ranges from 5 to $10 \%$, which is attributed by the authors ${ }^{9}$ to the insufficient energy exposure provided by the PDL.

In a clinical study, ${ }^{15}$ small-sized $<6 \mathrm{~mm}$ superficial BCC was successfully cured with a diode laser at a wavelength of $980 \mathrm{~nm}$ with an energy exposure (fluence) in the range from 200 to $800 \mathrm{~J} / \mathrm{cm}^{2}$ and with an exposure time of $0.1-1$ seconds.

CVL with a wavelength of $578 \mathrm{~nm}$ has the optimal parameters for the treatment of such vascular lesions as port-wine stains, hemangiomas, and telangiectasia. ${ }^{23}$ Therefore, the use of CVL, which allows for the selective heating of blood vessels, seems reasonable for the 
Table 2. The Laser Type for BCC Treatment, Laser Parameters, and Side Effects

\begin{tabular}{|c|c|c|c|c|c|c|c|}
\hline $\begin{array}{l}\text { Laser } \\
\text { Type }\end{array}$ & $\begin{array}{c}\text { Age of } \\
\text { Parents }(y)\end{array}$ & $\begin{array}{l}\text { The Size of } \\
\text { BCC }(\mathrm{mm})\end{array}$ & $\begin{array}{l}\text { Laser Settings (wavelength, } \\
\text { pulse length, fluence) }\end{array}$ & $\begin{array}{l}\text { Healing } \\
\text { Time }\end{array}$ & $\begin{array}{l}\text { No. of Treatment } \\
\text { Sessions }\end{array}$ & Side-Effects & Ref \\
\hline $\mathrm{CO}_{2}$ & $29-93$ & Up to 23 & $10,600 \mathrm{~nm}, 750 \mu \mathrm{s}, 7.5 \mathrm{~J} / \mathrm{cm}^{2}$ & $\begin{array}{c}\text { No } \\
\text { information }\end{array}$ & 1 & No information & 13 \\
\hline PDL & $29-88$ & 6 & $595 \mathrm{~nm}, 3 \mathrm{~ms} 7.5 \mathrm{~J} / \mathrm{cm}^{2}$ & 4 weeks & 1 & Purpura & 14 \\
\hline PDL & $30-90$ & 5 & $595 \mathrm{~nm}, 3 \mathrm{~ms}, 15 \mathrm{~J} / \mathrm{cm}^{2}$ & 3-4 weeks & $1-4$ & $\begin{array}{l}\text { Erythema Purpura, crusts } \\
\text { - post-inflammatory } \\
\text { hypopigmentation for } 3 \\
\text { months }\end{array}$ & 12 \\
\hline Diode & $35-91$ & $<6$ & $\begin{array}{c}980 \mathrm{~nm} 0.1-1 \mathrm{~s}, 200-800 \mathrm{~J} / \mathrm{cm}^{2} \\
0.2-0.9 \mathrm{~s}\end{array}$ & 7-10 days & 1 & Pain & 15 \\
\hline $\mathrm{Nd}: Y A G$ & $30-90$ & 5 & $\begin{array}{l}1,060 \mathrm{~nm}, 125-140 \mathrm{~J} / \mathrm{cm}^{2}, 7-10 \\
\mathrm{~ms}, 1.5-4.5 \mathrm{~ms}, 150-400 \mathrm{~J} / \mathrm{cm}^{2}\end{array}$ & 30 days & & Pain & 16,17 \\
\hline
\end{tabular}

treatment of BCC.

We compared the heating of vessels and perivascular tissue exposed to the radiation generated by CVL or the Diode laser. The comparison was based on the procedure of the simulation of blood vessel heating using Matlab software. The simulation relied upon the solution of partial differential equations with Femlab software and the use of the finite element method described in our previous reports. ${ }^{24}$

Figure 6 shows the calculated levels of the maximum tissue temperature at different depths under CVL and diode laser exposure. Due to the localization of the tissue heating, corresponding to the location of the BCC, the use of CVL seems to be a preferred variant of exposure than the diode laser. CVL provides higher tissue temperatures at commonly used fluence levels. The deep layers of tissue are not damaged, which increases the healing rate after the procedure.

Numerical simulation ${ }^{24}$ showed that the vessels of increased diameter to be heated by the CVL radiation more stronger than the surrounding tissue. For this reason, malignant BCC, which is characterized by high vascularization, ${ }^{20-21}$ is always heated by CVL laser radiation to a greater extent in comparison with healthy tissue. This effect provides an additional selectivity of the laser effect of the CVL for heating the BCC.

The treatment of the nasal BCC with a diode laser was related to the recurrence rate in the case of the nodular subtype from 19,3 to $50 \%$ and as much as $100 \%$ in an infiltrative subtype of BCC. ${ }^{15}$ As can be seen from Figure 6 , the calculated temperature of the tissue for a diode laser had a little change up to several $\mathrm{mm}$ from the skin surface. At the same time, more deeply located layers were exposed to excessive heating, which made the use of a diode laser unsafe, especially in the eye region.

Moskalik et $\mathrm{al}^{17}$ also indicated that due to the risk of damage to the organs of vision, the Nd: YAG laser treatment was prohibited for early forms of BCC localized on the eyelids. They also noted that one of the conditions for the successful treatment of skin cancer is exposure to laser radiation on the entire mass of the tumor.

At the same time, due to the high absorption of 578 $\mathrm{nm}$ wavelength by the blood, which falls into the high absorption band of hemoglobin, the CVL radiation allows working safely in the periorbital region, which was also demonstrated in our work. Therefore, the use of CVL ablative regime for BCC treatment is reasonable.

\section{Conclusion}

The use of high-energy CVL irradiation makes it possible to achieve significant success in treating patients with BCC in the periorbital region. The use of CVL on an outpatient basis may have some advantages in facilitating the introduction of this type of laser into medical practice. The use of CVL causes minimal cosmetic losses; as a result, it has significant advantages over other methods of treatment.

According to our research, CVL is an effective treatment for skin cancer at the stage of $\mathrm{T}_{1-2} \mathrm{~N}_{0} \mathrm{M}_{0}$ and provides excellent cosmetic results, including cases in the periorbital area.

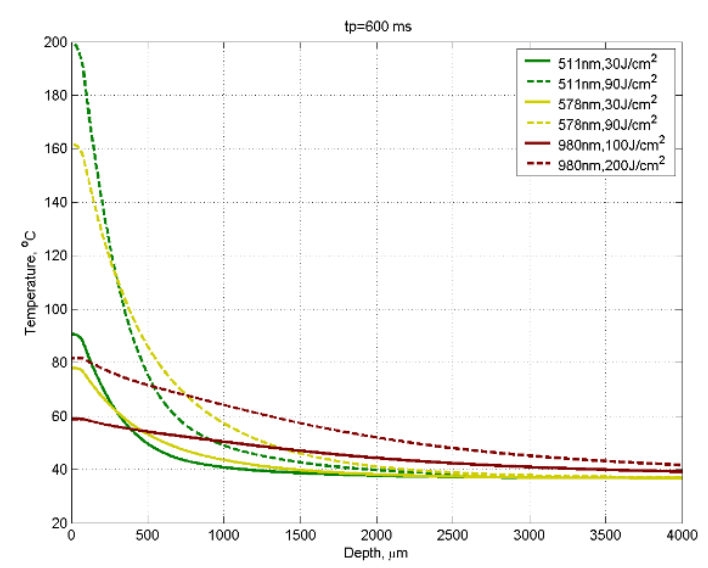

Figure 6. The calculated temperature distribution of the tissue at the end of the laser pulse $600 \mathrm{~ms}$ pulse duration) for the CVL $(511 \mathrm{~nm}$ and $578 \mathrm{~nm}$ ) and the diode laser $(980 \mathrm{~nm})$, the fluence value and exposure time are shown in the graph. 
We recommend that a CVL treatment should be used as primary therapy for BCC.

CVL treatment offers some advantages as follows:

- The selective absorption of the laser energy by the blood-filled tissue allows selective photo destruction of the lesion under ideal hemostatic conditions with minimal loss of normal tissue.

- The laser treatment can be performed under local anesthesia on an outpatient basis.

\section{Ethical Considerations}

Written informed consent was obtained from the patients before treatment.

\section{Conflict of Interests}

The authors would like to state that they do not have any conflict of interests to disclose.

\section{References}

1. Hollis DE, Scheibner A. Ultrastructural changes in epidermal Langerhans cells and melanocytes in response to ultraviolet irradiation, in Australians of Aboriginal and Celtic descent. Br J Dermatol. 1988;119(1):21-31. doi: 10.1111/j.1365-2133.1988.tb07097.x.

2. Schuch AP, Moreno NC, Schuch NJ, Menck CF, Garcia CC. Sunlight damage to cellular DNA: Focus on oxidatively generated lesions. Free Radic Biol Med. 2017;107:110-124. doi: 10.1016/j.freeradbiomed.2017.01.029.

3. Wu CS, Chen GS, Lin PY, Pan IH, Wang ST, Lin SH, et al. Tazarotene induces apoptosis in human basal cell carcinoma via activation of caspase-8/t-Bid and the reactive oxygen species-dependent mitochondrial pathway. DNA Cell Biol. 2014;33(10): 652-666. doi: 10.1089/dna.2014.2366.

4. Purohit NK, Robu M, Shah RG, Geacintov NE, Shah GM. Characterization of the interactions of PARP-1 with UVdamaged DNA in vivo and in vitro. Sci Rep. 2016;6:19020. doi: 10.1038/srep19020.

5. Kim M, Lee J, Park TJ, Kang HY.Paracrine crosstalk between endothelial cells and melanocytes through clusterin to inhibit pigmentation. Exp Dermatol. 2018;27(1):98-100. doi: 10.1111/exd.13443.

6. Quan T, Xu Y, Qin Z, Robichaud P, Betcher S, Calderone $\mathrm{K}$, et al. Elevated YAP and its downstream targets CCN1 and CCN2 in basal cell carcinoma: impact on keratinocyte proliferation and stromal cell activation. Am J Pathol. 2014;184(4):937-943. doi: 10.1016/j.ajpath.2013.12.017.

7. Bakshi A, Chaudhary SC, Rana M, Elmets CA, Athar M. Basal cell carcinoma pathogenesis and therapy involving hedgehog signaling and beyond. Mol Carcinog. 2017; 56(12):2543-2557. doi: 10.1002/mc.22690.

8. Pelosini L, Smith HB, Schofield JB, Meeckings A, Dithal A, Khandwala M. A novel imaging approach to periocular basal cell carcinoma: in vivo optical coherence tomography and histological correlates. Eye. 2015;29(8):1092. doi:10.1038/eye.2015.97.

9. Shahshahani MM, Ehsani A, Noormohammadpour P, Gholamali F. 595nm Pulsed dye laser: an alternative to treat basal cell carcinomas. J Lasers Med Sci. 2011;2(3):98-102. doi:10.22037/2010.v2i3.2353.
10. Parver DL, Dreher RJ, Kohanim S, Zimmerman P, Garrett G, Devisetty L, et al. Ocular injury after laser hair reduction treatment to the eyebrow. Arch Ophthalmol. 2012;130(10): 1330-1334. doi: 10.1001/archophthalmol.2012.1988.

11. Rigel DS, Robinson JK, Ross MI, Friedman R, Cockerell CJ, Lim H, Stockfleth E, Kirkwood JM, eds. Cancer of the Skin: Expert Consult. 2nd ed. Philadelphia, PA: Elsevier/ Saunders; 2011.

12. Minars N, Blyumin-Karasik M. Treatment of basal cell carcinomas with pulsed dye laser: a case series. J Skin Cancer. 2012;2012:286480. doi: 10.1155/2012/286480.

13. Hibler BP, Sierra H, Cordova M, Phillips W, Rajadhyaksha $\mathrm{M}$, Nehal KS, et al. Carbon dioxide laser ablation of basal cell carcinoma with visual guidance by reflectance confocal microscopy: a proof-of-principle pilot study. Br J Dermatol. 2016;174(6):1359-1364. doi: 10.1111/bjd.14414.

14. Eimpunth S, Oganesyan G, Hamman Sh, Lee RA, Jiang IB, Kim SS. Effectiveness of a 595-nm pulsed dye laser for the treatment of basal cell carcinoma using stacked-pulse session. J Am Acad Dermatol. 2014;70(5):ab134.

15. Derjabo AD, Cema I, Lihacova I, Derjabo LEDLL, Sroka $\mathrm{R}$, editors. $980 \mathrm{~nm}$ laser for difficult-to-treat basal cell carcinoma. Medical Laser Applications and Laser-Tissue Interactions VI. Munich: Optical Society of America; 2013.

16. Ortiz AE, Anderson RR, DiGiorgio C, Jiang SI, Shafiq F, Avram MM. An expanded study of long-pulsed $1064 \mathrm{~nm}$ Nd: YAG laser treatment of basal cell carcinoma. Lasers Surg Med. 2018;50(7):727-731. doi: 10.1002/lsm.22803.

17. Moskalik KK, Kozlow A, Demin E, Boiko E. Powerful neodymium laser radiation for the treatment of facial carcinoma: 5 year follow-up data. Eur J Dermatol. 2010; 20(6):738-742.

18. Gunes A, Yasar C, Tok L, Tok O. Two cases of anterior uveitis after laser eyebrow epilation. Cornea. 2015;34(1): 101-102. doi: 10.1097/ICO.0000000000000294.

19. Huang A, Phillips A, Adar T, Hui A. Ocular injury in cosmetic laser treatments of the face. J Clin Aesthet Dermatol. 2018;11(2):15.

20. Schuh S, Holmes J, Ulrich M, Themstrup L, Jemec GB, De Carvalho N, et al. Imaging blood vessel morphology in skin: dynamic optical coherence tomography as a novel potential diagnostic tool in dermatology. Dermatol Ther. 2017;7(2):187-202.

21. Stanton AW, Drysdale SB, Patel R, Mellor RH, Duff MJ, Levick JR, et al. Expansion of microvascular bed and increased solute flux in human basal cell carcinoma in vivo, measured by fluorescein video angiography. Cancer Res. 2003;63(14): 3969-3979.

22. Piskalkova T. Basal cell carcinoma: new opportunities for pathogenetic therapy. Klin Dermatol Venerol. 2014;6:4-8. doi: 10.17116/klinderma201464-8.

23. Klyuchareva SV, Ponomarev IV, Pushkareva AE. Numerical modeling and clinical evaluation of pulsed dye laser and copper vapor laser in skin vascular lesions treatment. J Lasers Med Sci. 2018;10(1):44-49. doi:10.15171/ jlms.2019.07.

24. Ponomarev IV, Topchiy SB, Kazaryan MA, Pushkareva AE, Klyuchareva SV, et al. Numerical Simulation Optimization of Selective Heating of Blood Vessels in "Port-Wine Stains" under Laser Irradiation in Various Modes. B Lebedev Phys Inst. 2018;45(7):204-208. doi:10.3103/S1068335618070035. 